\title{
High-Demand Leisure Activities Domain
}

National Cancer Institute

\section{Source}

National Cancer Institute. High-Demand Leisure Activities Domain. NCI Thesaurus. Code C129990.

A domain of the Activity Card Sort (ACS) related to high physical demand leisure activities that may be part of an individual's routine such as bicycling, woodworking, and hiking. 